\title{
Publisher Correction: Metrology for the next generation of semiconductor devices
}

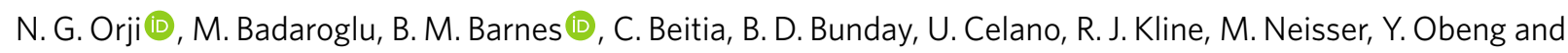
A. E. Vladar

Correction to: Nature Electronics https:/doi.org/10.1038/s41928-018-0150-9, published online 12 October 2018.

In the version of this Review Article originally published, the labelling of the reflected beam in Fig. 4a was incorrect, and should have been as shown below. This has now been corrected in the Review Article.
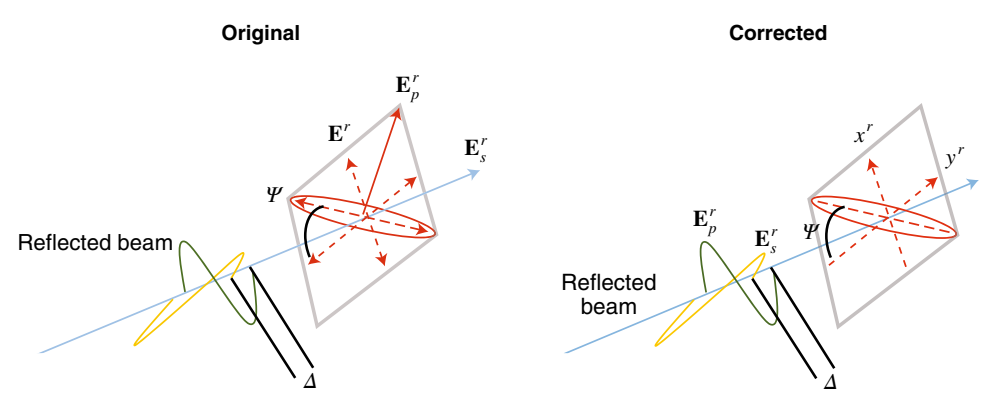

Fig. 4a l Original and corrected. 